\title{
Effect of outdoor open pack space allowance on the behavior of freestall-housed dairy cows
}

\author{
A. M. C. Smid, (D) D. M. Weary, (1) and M. A. G. von Keyserlingk* (1) \\ Animal Welfare Program, Faculty of Land and Food Systems, University of British Columbia, Vancouver, V6T 1 Z6 Canada
}

\begin{abstract}
Providing dairy cows access to pasture is desirable, given their strong motivation for pasture access, but this practice is hindered by several practical constraints, including lack of available pasture. An alternative to pasture is an outdoor area that is bedded with a soft material such as sand or wood chips that requires less space than pasture, given the absence of soil or grass that can otherwise be damaged by cow traffic. However, little is known about space requirements for alternative outdoor areas. This study investigated how space allowance affected cow preference to be outdoors as well as cow behavior on an outdoor pack. A total of 3 groups of 24 pregnant, lactating, healthy Holstein cows were used. Each group was given $3 \mathrm{~d}$ for social dynamics to stabilize; during this time cows were kept indoors in a freestall pen. A habituation phase of $5 \mathrm{~d}$ followed, where animals were given free access to the outdoor pack with a space allowance of $16 \mathrm{~m}^{2} /$ cow. Cows were moved outside (if not already outdoors) at set times each day during the habituation phase (i.e., 5 times during the first $2 \mathrm{~d}$ and 2 times during the last $3 \mathrm{~d}$ ). Cows were then given free access to the outdoor pack, but space allowance was changed every day. A total of 13 different space allowances were randomly applied, without replacement, ranging from 4 to $16 \mathrm{~m}^{2} /$ cow in $1-\mathrm{m}^{2}$ increments. Using continuous video recordings, the location of the cows (i.e., in the freestall barn or on the outdoor pack) as well as displacements from a lying position on the outdoor pack were scored. Standing and lying behaviors were automatically measured using HOBO data loggers (Onset, Cape Cod, MA). Over the 24-h period, cows spent more time outside with increasing space allowance, but this result was driven almost entirely by the increased time spent outdoors during the nighttime hours. During the night, space allowance did not influence the number of displacements from lying on the outdoor pack or the proportion of
\end{abstract}

Received June 4, 2019.

Accepted November 12, 2019.

*Corresponding author: nina@mail.ubc.ca time on the outdoor pack that cows spent lying down. Our results indicate that cows use an outdoor bedded pack mostly at night and that the time spent outside at night increases with increasing space allowance. Providing an outdoor bedded pack should be considered when designing dairy cattle housing systems.

Key words: animal welfare, free range, outdoor area, exercise yard, bedded pack

\section{INTRODUCTION}

Access to pasture is viewed as important for dairy cows in many countries (for The Netherlands, see Boogaard et al., 2008; for the United States and Canada, see Schuppli et al., 2014; for Brazil, see Hötzel et al., 2017). Cows are highly motivated to access pasture, especially at night (Charlton et al., 2013; von Keyserlingk et al., 2017). However, pasture access for dairy cows is not always perceived as feasible. Farmers can face a range of practical constraints, including lack of available pasture, particularly as farm size increases (Robbins et al., 2016). In addition, pasture access may not be feasible during parts of the year, for example when soil is wet and subject to damage from cow traffic. One alternative to pasture is a bedded outdoor pack; that is, an open area with soft bedding where cows can move and lie down more freely than they can in a freestall barn. Given the absence of soil or grass in these alternative outdoor areas, outdoor packs generally require less space than pasture and can be used year-round. Several studies have investigated the effect of space allowance on the behavior of dairy cows. For example, Schütz et al. (2015) reported that a minimum of $6.0 \mathrm{~m}^{2}$ of space allowance per cow was needed on a rubber pad during an 18-h stand-off period, when cows are kept off pasture in wet weather to prevent damage to grass, to maintain daily lying times similar to those observed when cows were housed on pasture. When cows were provided less space (i.e., 3 or $4.5 \mathrm{~m}^{2}$ of rubber mat per cow), the reduction in lying times and lying bouts was thought to be due to increased agonistic behavior. Nielsen et al. (1997) found that heifers given $1.8 \mathrm{~m}^{2} /$ animal of lying space on an indoor straw 
pack exhibited more agonistic interactions, including displacements from lying position, than when they were given 2.7 or $3.6 \mathrm{~m}^{2}$ /animal. However, these studies all investigated the effect of space allowance when cows did not have the option to access another area. To our knowledge, no study has investigated how space allowance on an outdoor open pack affects cow behavior and cow preference to be outdoors, when cows are given a free choice to access this secondary area from a freestall barn.

The aims of this study were to investigate how space allowance on an outdoor open pack affects (1) the preference of freestall-housed cows to be outdoors, (2) the number of displacements from lying on the outdoor pack, and (3) the proportion of outdoor time that cows spent lying. We predicted that at greater space allowances cows would spend more time outside, especially during the night when outdoor access is most popular (Legrand et al., 2009; Charlton et al., 2013; von Keyserlingk et al., 2017). We also predicted that at greater space allowances cows would spend more time lying down outside and would engage in fewer displacements from lying interactions.

\section{MATERIALS AND METHODS}

\section{Cows and Treatment}

This experiment was conducted between May and July 2017 at the Dairy Education and Research Centre (Agassiz, BC, Canada) of the University of British Columbia. The University of British Columbia Animal Care Committee approved the experiment and all procedures (Protocol A15-0082).

A total of 72 pregnant, lactating Holstein cows were randomly selected from the herd and assigned to 3 groups (24 animals per group) that were run sequentially. Groups were balanced (mean \pm SD) for parity (3.0 \pm 0.1 ), DIM $(217 \pm 8)$, projected 305 -d milk production $(11604 \pm 263)$, BCS $(3.4 \pm 0.0$, scored on a 5 -point scale, where $1=$ thin and $5=$ obese, with quarter-point increments, following Edmonson et al., 1989), and gait score $(1.9 \pm 0.0$ scored on a 5 -point scale, where $1=$ healthy and $5=$ severely lame, following Flower and Weary, 2006). Cows that were in early lactation $(<100$ $\mathrm{DIM})$, thin $(\mathrm{BCS} \leq 2)$, or severely lame (gait score $\geq 4$ ) were not enrolled. In addition, given that many cows of this herd had been enrolled in previous trials investigating an outdoor open pack, groups were also balanced for experience with an outdoor pack (13 to 15 experienced cows per group).

Animals were enrolled in the study for $21 \mathrm{~d}$. At formation of each group (d 1), animals were given $3 \mathrm{~d}$ to allow for the social dynamics of the group to stabilize (see von Keyserlingk et al., 2008), followed by a 5-d habituation phase in which animals were given access to the outdoor pack with a space allowance of $16 \mathrm{~m}^{2} /$ cow, the highest space allowance tested in this study, to minimize any negative association with the outdoor environment by cows. To ensure that cows were familiar with the outdoor pack, they were moved outside (if they were not already outdoors) during the first 2 habituation days at 1030,1400, 2000, 2300, and 0600 $\mathrm{h}$, and during the last $3 \mathrm{~d}$ at 1100 and $2300 \mathrm{~h}$. Animals were kept outside for approximately $5 \mathrm{~min}$, after which they were allowed to return to the barn. After the habituation period, when cows returned to their pen after morning milking, the treatments commenced.

Thirteen different space allowances in the outdoor pack were tested, ranging from 4 to $16 \mathrm{~m}^{2} /$ cow in $1-\mathrm{m}^{2}$ increments (see Figure 1). Given that we lacked predictions about specific space allowances, we tested the effect of space as a continuum, considering a wide range of values. Based in part on the work of Schütz et al. (2015), the minimum space allowance on the outdoor pack was set at $4 \mathrm{~m}^{2} /$ cow. The maximum space allowance on the outdoor pack was set at $16 \mathrm{~m}^{2} /$ cow, which is considerably more space per cow than the current recommendation set by the Canadian Code of Practice (NFACC, 2009) for open packs. Space allowance was applied randomly each day, without replacement, at approximately $0715 \mathrm{~h}$, while the cows were being milked. In addition, the indoor feeding area was blocked with a chain, and all 24 cows were taken to the outdoor pack once they had returned from milking together. They were then held on the outdoor pack for 5 min before being moved indoors, to allow some time to habituate to the new space allowance.

Animals were milked twice daily in a double-12 parallel milking parlor, between 0715 and $0745 \mathrm{~h}$ in the morning and between 1700 and $1730 \mathrm{~h}$ in the afternoon. Cows were out of their pen for approximately $45 \mathrm{~min}$ during milking.

\section{Housing, Management, and Diet}

Indoor Area. The indoor freestall pen $(13.2 \times$ $12.6 \mathrm{~m})$ was located in a mechanically ventilated $\left(72^{\prime \prime}\right.$ Artex Storm Fan, Artex Barn Solutions, Abbotsford, BC, Canada) wooden-frame freestall barn $(42 \times 93 \mathrm{~m})$ with a north-south orientation and curtained sidewalls. Indoor space allowance (i.e., total space minus lying space) was $3.8 \mathrm{~m}^{2} /$ cow when all cows were inside. The experimental pen consisted of 24 lying stalls, configured in 3 rows of 8 stalls, filled with $\pm 40 \mathrm{~cm}$ of washed river sand, replenished biweekly. Stalls were raked twice daily, when cows were gone for milking; stalls were divided using Dutch-style partitions spaced $1.2 \mathrm{~m}$ 
center-to-center, with the neck rail placed $1.4 \mathrm{~m}$ above the stall surface and $1.7 \mathrm{~m}$ from the inside of the rear curb. The brisket board $(0.15 \mathrm{~m}$ high) was positioned $1.8 \mathrm{~m}$ from the inside of the rear curb, which was $0.2 \mathrm{~m}$ in height as measured from the alley floor. The concrete alleys were cleaned 6 times daily with an automated scraper; crossover alleys were manually cleaned twice a day when cows were away from the pen during milking. The pen had a post-and-rail feed barrier (see Huzzey et al., 2006), allowing $53 \mathrm{~cm}$ of feed bunk space per cow.

Cows were offered a TMR, formulated following National Research Council guidelines (NRC, 2001) to meet or exceed the requirements of a $658-\mathrm{kg}$ Holstein producing $36 \mathrm{~kg}$ of milk per day. The TMR consisted of $34 \%$ corn silage, $44 \%$ concentrate mash, $6.5 \%$ grass silage, $7 \%$ grass hay, $6.5 \%$ alfalfa hay, and $2 \%$ wheat straw on a DM basis. The TMR was available ad libitum inside during the complete experimental period. Fresh feed was provided between 0630 and $0700 \mathrm{~h}$ and between 1530 and $1600 \mathrm{~h}$. Feed was pushed up at approximately 1045,1845 , and $2230 \mathrm{~h}$, and orts were taken away at approximately $0515 \mathrm{~h}$. Animals had ad libitum access to fresh water, provided in a self-filling water trough located on the crossover alley.
Outdoor Area. The outdoor open pack (Figure 1) was $384 \mathrm{~m}^{2}(12 \times 32 \mathrm{~m})$ with a gravel base covered with a base layer of approximately $20 \mathrm{~cm}$ of washed river sand and topped with approximately $20 \mathrm{~cm}$ of pole peelings (i.e., wood chips, a by-product of the forestry industry that is coarser than sawdust; see Appendix Figure A1). Space allowance was varied by adjusting movable electric fencing (see Figure 1). The path connecting the freestall pen and the outdoor pack were cleaned every morning and afternoon while the cows were being milked.

\section{Behavioral Measures}

Three dome video cameras (Panasonic WVCW504SP, Sentinel Ultra-Zoom with Pan 1070 outdoor video camera, Panasonic Corporation of North America, Newark, NJ) were attached at a height of $6 \mathrm{~m}$ on the outdoor wall of the barn, to collectively provide an overview of the entire outdoor pack. Above the experimental pen, 2 dome video cameras were positioned $8 \mathrm{~m}$ above the pen to provide an overview of the indoor lying area. Two additional video cameras (Panasonic WVCP-470, Panasonic Corp.) were placed $6 \mathrm{~m}$ above

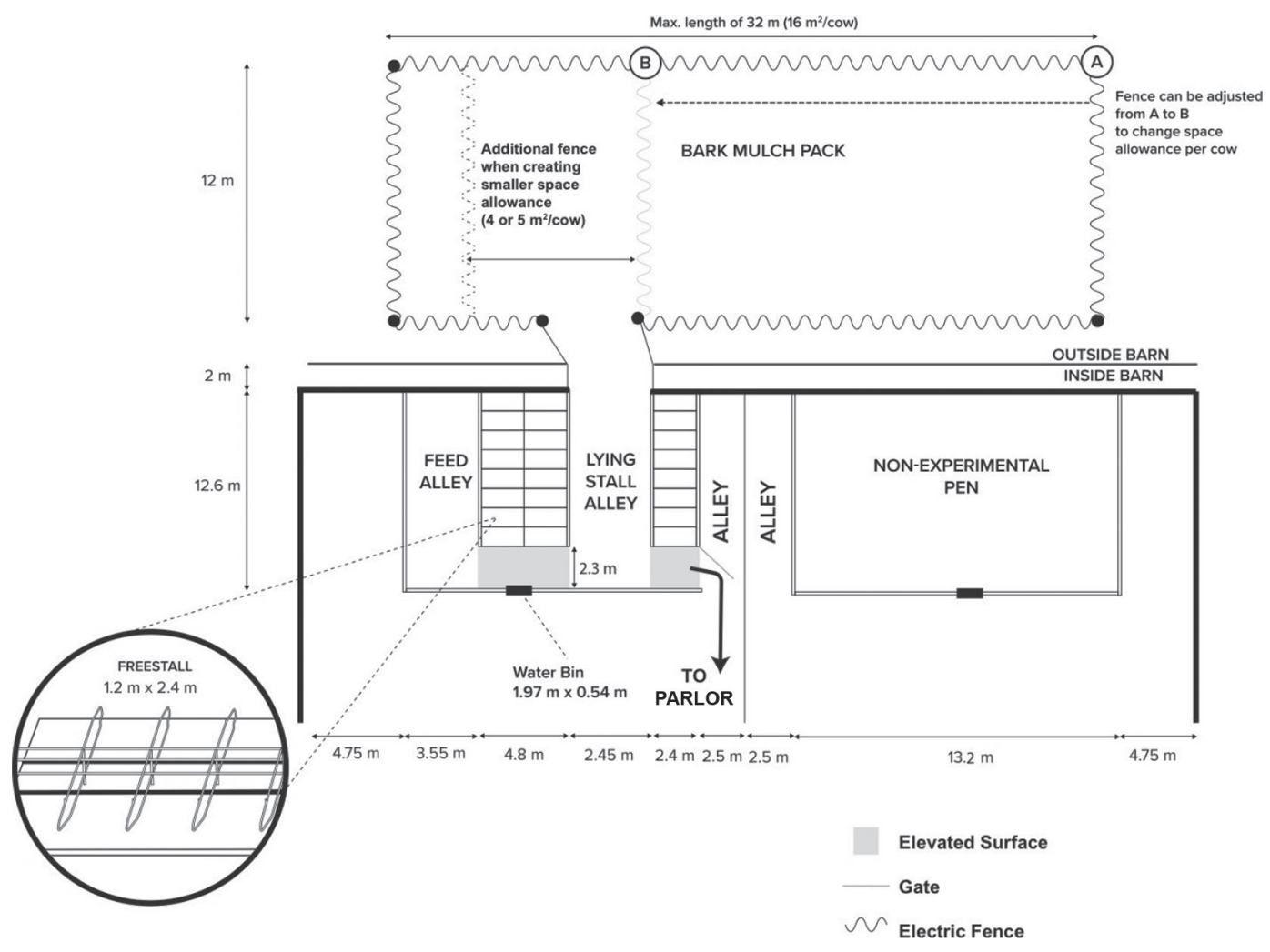

Figure 1. Schematic of experimental areas used to test the preferences of lactating dairy cows to be in the freestall barn or on the outdoor pack when provided various space allowances outside. Max. = maximum. 
the feed bunk of the experimental pen to provide an overview of the feeding area. All video recordings were stored using a GeoVision 1480 digital recorder (USA Vision Systems, Irvine, CA). Infrared lights (BR38 Red Incandescent Flood Light 100 W, Globe Electric Company Inc., Montréal, Canada) were placed adjacent to each camera to facilitate observation of the cows at night. Each cow was marked with hair dye to facilitate individual recognition.

The location of animals (in the freestall pen or on the outdoor pack) and displacements from a lying position on the outdoor pack were scored using continuous video observations. A displacement was defined by any movement or physical contact of the "actor" cow that was standing idle or walking within a body length's distance from a lying "reactor" cow, toward the reactor cow, resulting in the reactor cow transitioning to a standing position (4 feet on the ground) within $15 \mathrm{~s}$. Interobserver reliability for this measure was $\mathrm{R}^{2}=0.96$. Given difficulties with reliably observing more detailed social behaviors when cows were on the outdoor pack, we chose only to score displacements from the lying position.

Lying time was quantified with HOBO data loggers (HOBO Pendant G, Onset, Cape Cod, MA; UBC AWP, 2013) programmed to record cow posture (lying or standing) in 1-min intervals (validated by Ledgerwood et al., 2010). The logger was attached to 1 rear leg of each cow on the last day of the habituation period.

\section{Climatic Measures}

Average hourly air temperature $\left({ }^{\circ} \mathrm{C}\right)$, hourly maximum relative humidity (\%), and rainfall $(\mathrm{mm})$ were recorded at the Environment Canada weather station in Agassiz, BC, located approximately $400 \mathrm{~m}$ from the UBC Dairy Education and Research Centre. Temperature-humidity index (THI) was calculated as THI = $(1.8 \mathrm{~T}+32)-[(0.55-0.0055 \mathrm{RH}) \times(1.8 \mathrm{~T}-26)]$, where $\mathrm{T}=$ air temperature $\left({ }^{\circ} \mathrm{C}\right)$ and $\mathrm{RH}=$ relative humidity (\%; Ravagnolo et al., 2000). Daily temperature averaged $17.2 \pm 2.9{ }^{\circ} \mathrm{C}$ (mean $\pm \mathrm{SD}$; range: 11.6 to $22.2^{\circ} \mathrm{C}$ ), and relative humidity averaged $67.5 \pm 10.1 \%$ (range: 48.5 to $87.8 \%$ ). The THI averaged $61.5 \pm 3.7$ (range: 53.4 to 67.9). Precipitation was recorded on 6 out of 33 complete experimental (i.e., 24-h) days that were included in the analysis (i.e., some days or day periods had to be excluded; see below) and averaged $6.2 \pm 7.3 \mathrm{~mm}$ (range: 0.2 to $19.8 \mathrm{~mm}$ ).

\section{Statistical Analysis}

One complete 24-h period (space allowance: $6 \mathrm{~m}^{2}$ ) from group 1 and one complete 24-h period (space allowance: $7 \mathrm{~m}^{2}$ ) from group 3 were excluded due to a cow in the group being in heat. Two nights (space allowances: 5 and $9 \mathrm{~m}^{2}$, groups 2 and 3, respectively) were excluded due to technical errors, and 2 days (space allowances: 5 and $16 \mathrm{~m}^{2}$, groups 1 and 3, respectively) were excluded due to the delivery of new pole peelings to the outdoor pack on one day and of new sand bedding to the freestall area on another. One cow (group 2) was diagnosed with severe mastitis, accompanied with fever and anorexia, on the fifth experimental day. This cow was moved to a hospital pen and was not included in the analyses. Three other cows (1 from group 1, 2 from group 3) were also diagnosed with mastitis but showed no secondary signs and thus remained in the study. A total of 7 cows (2 cows from group 1, 4 from group 2, and 1 from group 3) were excluded from the analysis of lying behavior due to technical problems with the HOBO data loggers (water damage, loss of battery power, or other problems).

Data were summarized by group and treatment (i.e., space allowance), with group as the experimental unit, and analyzed using SAS (version 9.4, SAS Institute Inc., Cary, NC). Data were analyzed as totals over the 24-h period, as well as separately by day (designated as the time between morning and afternoon milkings) and night (designated as the time between afternoon and morning milkings). Model residuals were visually assessed for normality; 2 outlier days were identified and deleted from all analyses. During these 2 days (both in group 1), cows spent $\pm 2 \mathrm{~h}$ outside during the day, which is much higher than the average time spent outside during the day. Both days were testing greater space allowances (14 and $15 \mathrm{~m}^{2} / \mathrm{cow}$ ) and had lowerthan-average THI values, and on one of these days precipitation was recorded. A mixed model was used to test the effect of outdoor space allowance on time spent outside and frequency of visits to the outdoor pack, as well as on various behaviors: the number of displacements on the outdoor pack, lying time outside, and daily lying time. With regard to lying time outside, days during which cows did not go outside were not included in the analysis, as we were specifically interested in lying behavior once cows had made the choice to go outside. The linear and quadratic effects of space allowance were included as fixed effects. The quadratic term was added because we expected that the effect of additional space would decline at greater space allowances. A random intercept with group as subject was included, and an autoregressive type 1 covariance structure was specified. The correlation between several environmental conditions (air temperature, relative humidity, precipitation, and THI) was investigated using a Spearman correlation. Air temperature, relative humidity, and THI were highly correlated $(\mathrm{r}>0.7)$. 
Because THI is a composite measure of air temperature and relative humidity, we retained THI in the analysis and dropped the air temperature and relative humidity. In all models, THI as well as its quadratic term and order of testing the different space allowances were included as covariates. Significance was declared at $P$ $<0.05$ and trends at $P<0.10$.

\section{RESULTS}

\section{Time Spent Outdoors and Visits to the Outdoor Pack During the Day and Night}

With increasing space allowance, cows spent more time on the outdoor pack $\left(F_{1,23}=6.27, P=0.0198\right.$, slope $=0.5 \pm 0.2$ ), with the magnitude of this effect tending to decline with increasing space allowance $\left(F_{1,23}=3.59, P=0.0706\right.$, slope $\left.=-0.02 \pm 0.01\right)$. This was driven by the increased time cows spent outdoors during the nighttime hours, so day and night periods were analyzed separately.

During the day, space allowance did not affect the time cows spent outside $\left(F_{1,25}=1.08, P=0.3095\right.$; Figure $2 \mathrm{~A}$ ). However, increasing THI decreased the time cows spent outside $\left(F_{1,25}=22.42, P<0.001\right.$, slope $=$ $-0.9 \pm 0.2)$, with the magnitude of this effect increasing with increasing THI $\left(F_{1,25}=21.34, P<0.001\right.$, slope $=0.007 \pm 0.001$ ).

At night cows spent more time outside with increasing space allowance $\left(F_{1,27}=7.68, P=0.0100\right.$, slope $=$ $0.5 \pm 0.2)$, with the quadratic term reflecting a diminishing effect $\left(F_{1,27}=5.32, P=0.0290\right.$, slope $=-0.02 \pm$ 0.01; Figure 2B). In addition, increasing THI decreased the time cows spent outside at night $\left(F_{1,27}=6.34, P=\right.$ 0.0180 , slope $=-2.7 \pm 1.1$, with the magnitude of this effect increasing at higher values of THI $\left(F_{1,27}=6.43\right.$, $P=0.0173$, slope $=0.02 \pm 0.01$ ).

The frequency of visits to the outdoor pack did not differ with space allowance during the day $\left(F_{1.25}=\right.$ $1.25, P=0.2734)$ or night $\left(F_{1,27}=0.19 P=0.6645\right)$. However, during the day, increasing THI decreased the number of visits to the outdoor pack $\left(F_{1,25}=12.20, P\right.$ $=0.0018$, slope $=-1.0 \pm 0.3$, again with a positive quadratic effect $\left(F_{1,25}=11.90, P=0.0020\right.$, slope $=$ $0.008 \pm 0.002$ ).

\section{Displacements from Lying and Lying Time}

Because cows generally spent little time outside during the day, the effects of outdoor space allowance on displacements from lying and lying time on the outdoor pack were investigated for the nighttime only. Outdoor space allowance did not affect the number of displacements from lying on the outdoor pack $\left(F_{1,27}=1.26, P\right.$
$=0.2708)$. In addition, the proportion of outdoor time that cows spent lying down was not affected by space allowance $\left(F_{1,27}=1.82, P=0.1886\right)$. However, higher THI decreased the proportion of outdoor time cows spent lying down $\left(F_{1.27}=5.33, P=0.0288\right.$, slope $=$ $-0.2 \pm 0.1$, with the magnitude of this effect increasing at higher values of THI $\left(F_{1,27}=5.65, P=0.0248\right.$, slope $=0.002 \pm 0.001$ ). Total daily lying time (inside the freestall barn and on the outdoor pack) was not affected by outdoor space allowance $\left(F_{1,23}=0.01, P=\right.$ $0.9231)$ but increased with higher THI $\left(F_{1,23}=10.73\right.$, $P=0.0033$, slope $=2.0 \pm 0.6)$, with the magnitude of this effect decreasing at higher values of THI $\left(F_{1,23}=\right.$ $11.80, P=0.0023$, slope $=-0.017 \pm 0.005)$.

\section{DISCUSSION}

Cows spent more time outside with increasing outdoor space allowance over the 24 -h period. This effect was driven by cows spending more time outside with increasing outdoor space allowance during the night, and the effect was absent during the day. Dairy cow preference for outdoor access during the night has been found in many other studies (for studies on pasture, see Legrand et al., 2009; Charlton et al., 2011, 2013; von Keyserlingk et al., 2017; on wood-chip pack, see Smid et al., 2019). Increasing outdoor THI values decreased the time cows spent outside; the availability of mechanical ventilation inside the barn may at least partially explain this result. Other studies conducted in the same season and geographic region found a decrease in the amount of time cows spent on pasture with increasing outdoor THI during the day (Legrand et al., 2009; Falk et al., 2012). Temperature-humidity index values are generally higher during the day than during the night (Tucker et al., 2008), and cows avoid solar radiation (Schütz et al., 2009); these factors together may explain the preference of cows for night versus day outdoor access.

Outdoor space allowance did not affect the frequency of visits to the outdoor pack during the day or night. During the day, increasing outdoor THI decreased the frequency of visits to the outdoor pack. Given that cows spent less time outside during the day than during the night, the effect of THI on frequency of visits to the outdoor pack may have been stronger during the day than during the night. During the night, when cows spent more time outdoors, outdoor space allowance had a positive effect on the time outdoors, with a quadratic term indicating a decreasing magnitude of this effect. This result suggests that increasing outdoor space allowance affects cow behavior, with diminishing returns. Hence, the range of space allowances chosen for this study seem to have provided cows with enough 
variation in outdoor space allowance to assess the effect on usage. Indoor space allowance could also have affected cow behavior. For animal welfare reasons, the stocking density in the freestall barn was set at $100 \%$. Given that overstocking leads to increases in aggressive interactions between cows and reductions in lying time (Fregonesi et al., 2007; Krawczel et al., 2012), the effects of access to an outdoor pack would likely have been more pronounced under overstocking conditions.
In contrast to our prediction, we found no effect of outdoor space allowance on the number of lying displacements between cows on the outdoor pack. In general, smaller space allowances are related to higher levels of agonistic interactions between cattle (Nielsen et al., 1997; Talebi et al., 2014; Tresoldi et al., 2015). However, the cows in the current study always had free access to the freestall barn. Thus, individual cows could avoid these interactions by simply moving in-

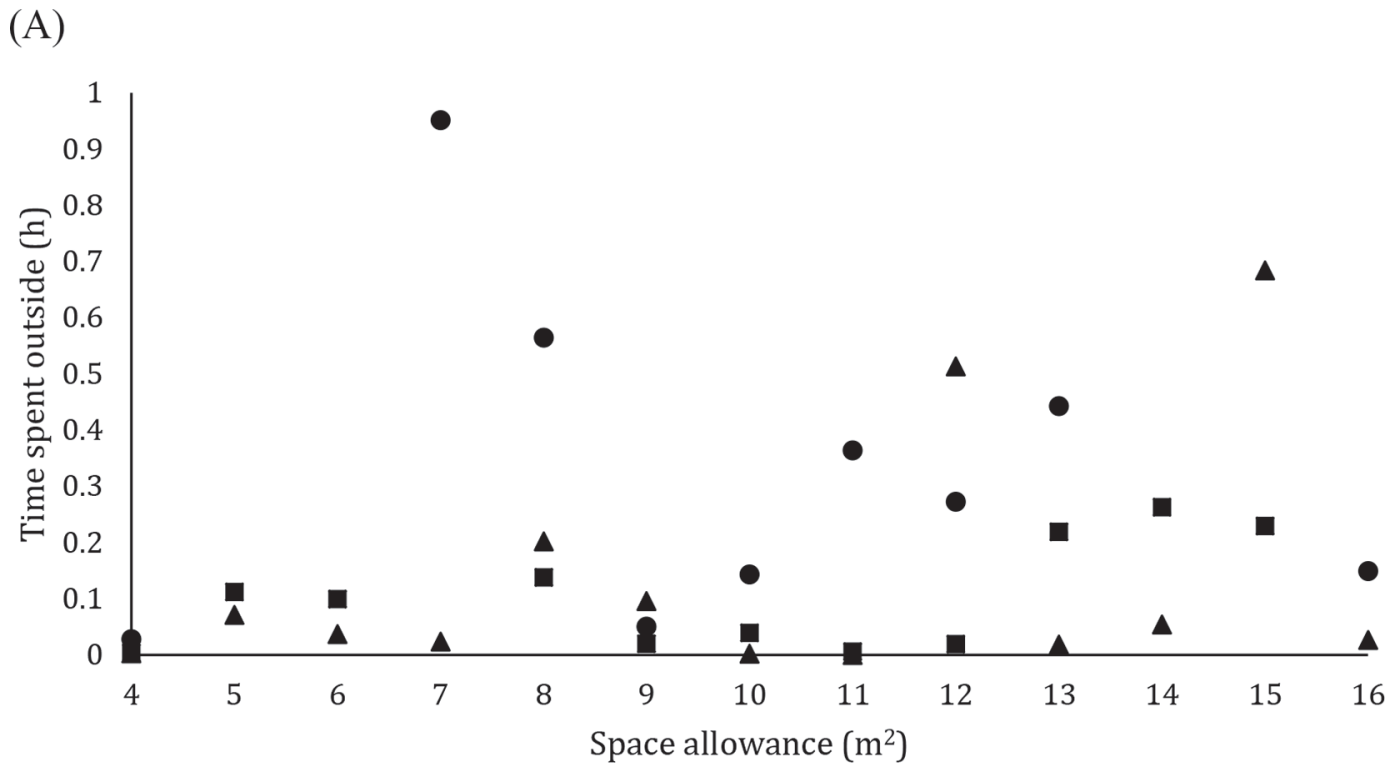

(B)

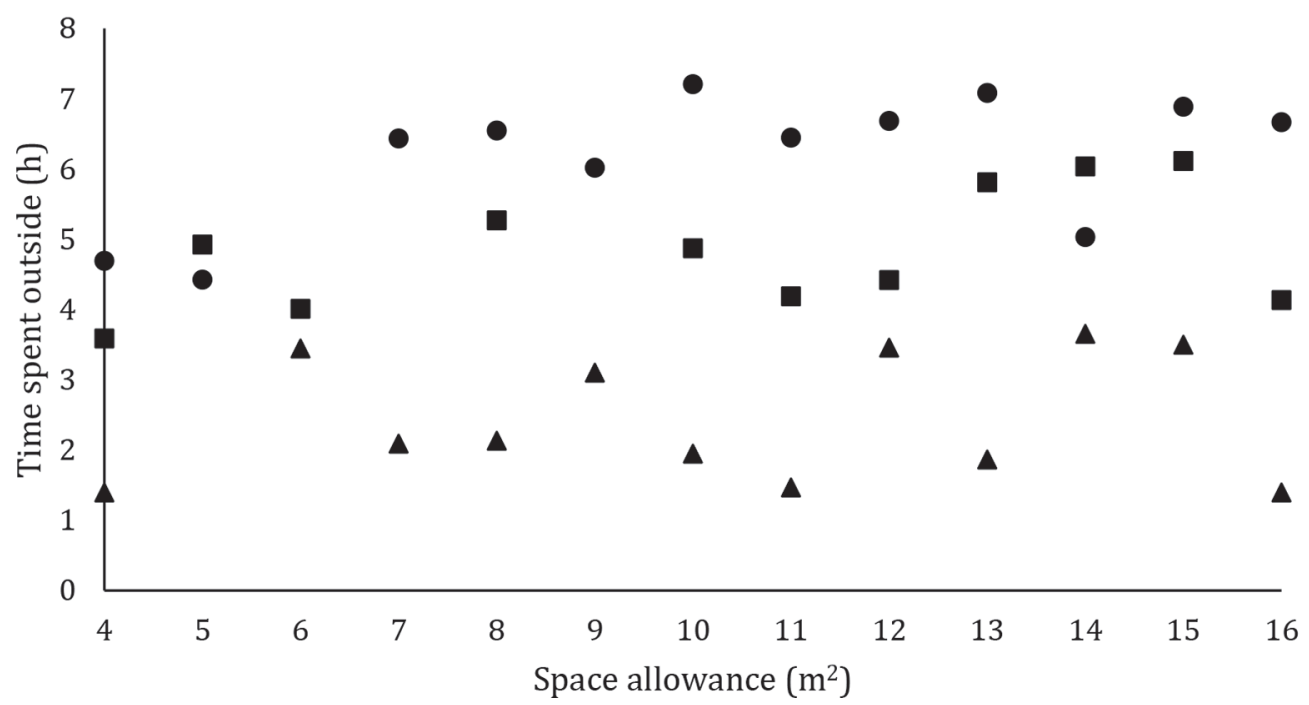

Figure 2. Average time lactating dairy cows $(\mathrm{n}=3$ groups of 24 cows; group 1 indicated by round dots; group 2 indicated by triangles; group 3 indicated by squares) spent on the outdoor pack with various space allowances (A) during the day (between morning and afternoon milking) and (B) during the night (between afternoon and morning milking). Over all space allowances, time spent outside during the day (mean \pm SD): $0.3 \pm 0.3 \mathrm{~h}, 0.1 \pm 0.2 \mathrm{~h}$, and $0.1 \pm 0.1 \mathrm{~h}$ for groups 1,2 , and 3 , respectively. Time spent outside during the night (mean $\pm \mathrm{SD}$ ): $6.2 \pm 0.9 \mathrm{~h}, 2.5$ $\pm 0.9 \mathrm{~h}$, and $4.9 \pm 0.9 \mathrm{~h}$ for groups 1,2 , and 3 , respectively. 
doors. The type of agonistic interactions may also have played a role. Schütz et al. (2015) found a decrease in the number of agonistic interactions between cows with increasing space allowance when confined to an outdoor space covered with a rubber mat. This effect was driven by interactions between standing cows; displacements from a lying position were uncommon. In addition, only nonaggressive interactions toward lying cows were affected by space allowance; aggressive interactions toward lying animals were not affected. Given the challenge of discriminating between aggressive and nonaggressive interactions on the outdoor pack, our definition of a displacement involved any type of interaction between cows, aggressive or nonaggressive, that resulted in the reactor cow changing from a lying to a standing position. It is unknown whether space allowance influenced other types of agonistic interactions than displacements from a lying position. Val-Laillet et al. (2008) showed that more than $85 \%$ of all agonistic interactions between cows housed in a stable group in the freestall barn occurred at the feed bunk. Given that no feed was provided outdoors, this may also partially have accounted for the lack of an effect.

No difference in the proportion of outdoor time that cows spent lying down during the night was found over the different outdoor space allowances. Generally, less space allowance corresponds to lower lying time (Hindhede et al., 1996; Fisher et al., 1997; Schütz et al., 2015). However, Mogensen et al. (1997) found no difference in lying time between heifers housed in straw-bedded packs with 1.5 or $3.0 \mathrm{~m}^{2}$ space allowance per heifer, but the authors did note increased lying synchrony at the greater space allowance, something they found that heifers prioritized. Nielsen et al. (1997) found no effect of space allowance of an indoor open pack on lying time in heifers but found that heifers would only lie outside of the bedded lying area when given the smallest lying space of $1.8 \mathrm{~m}^{2}$ /animal, suggesting that cattle try to maintain their lying times. Higher stocking density also reduces lying time in cows kept in freestalls (Fregonesi et al., 2007; Telezhenko et al., 2012). A possible explanation of our lack of effect of space allowance on the proportion of outdoor time that cows spent lying down is that cows may have preferred to stand outside, given the softer flooring than what was available indoors. As suggested by Fregonesi et al. (2004), cows may prefer to stand on soft surfaces rather than hard. Total daily lying time did not change with increasing space allowance, which implies that cows compensated for the lower absolute time spent lying outdoors by lying indoors. Lying is a highly motivated behavior in cows (Munksgaard et al., 2005; Tucker et al., 2018), so it is not surprising that cows maintained their lying time. Increasing outside THI decreased the proportion of outdoor time that cows were lying during the night, likely because a standing posture may facilitate heat dissipation (Wang et al., 2018). Interestingly, increasing outdoor THI increased total daily lying time. As the cows spent more time inside with higher THI values, they may have elected to lie down rather than stand on the concrete floor indoors (Fregonesi et al., 2004). The use of mechanical ventilation inside the barn may have facilitated heat dissipation and thereby minimized the effect of THI on lying time.

Use of the outdoor pack may have been influenced by the presence of electric fencing, as this type of fencing likely resulted in cows standing away from the fence, reducing the effective space allowance. This effect might be especially important at smaller space allowances.

Given individual variation in preference of cows to access the outdoor pack, it is important to provide cows a choice to access the outdoors, as opposed to keeping cows on an outdoor open pack. The provision of a choice to access various environments also provides cows with control over their environment, which is thought to be important for animal welfare (Franks and Higgins, 2012; Franks, 2019). Given the open space outdoors, where cows may have been more vulnerable to negative interactions, it is possible that lower-ranking cows spent less time outdoors than did higher-ranking cows. Our study was not designed to investigate the effect of dominance status on preference for the outdoor pack, but the possibility of this effect emphasizes the importance of providing cows choice. Results of a study by Haskell et al. (2013) suggested that low-ranking cows used a concrete loafing area to avoid higher-ranking cows. However, an outdoor area with concrete flooring may not have been as attractive to cows as an outdoor bedded pack. Consequently, it is possible that an outdoor bedded pack will be used more by high-ranking than by low-ranking cows. We recommend future research to investigate the relationship between dominance status and preference to access various outdoor areas.

\section{CONCLUSIONS}

Freestall-housed cows spent more time outdoors with increasing space allowance on an outdoor open pack during the night but not during the day. When tested during the night, outdoor space allowance did not affect the number of lying displacements on the outdoor pack or the proportion of time outdoors that cows spent lying. Given the partial preference of dairy cows to access an outdoor open pack, providing an outdoor bedded pack should be taken into account when designing dairy cattle housing systems where pasture is not feasible. 


\section{ACKNOWLEDGMENTS}

We thank the staff of the University of British Columbia's Dairy Education and Research Centre (Agassiz, BC, Canada) for their help with the experiment. We also thank the members of the University of British Columbia's Animal Welfare Program (Vancouver, BC, Canada), in particular Jessica St.-Pierre, Stephanie Boeve, and Shabnaz Mokhtarnazif, for their help with the experiment and video analysis. In addition, we thank Agriculture and Agri-Food Canada (Agassiz, BC) for providing us access to hourly weather data. A. M. C. Smid was supported in part by the Irving K. Barber Victory in Europe scholarship (Victoria, BC, Canada). M. A. G. von Keyserlingk and D. M. Weary are supported by Canada's Natural Sciences and Engineering Research Council (NSERC, Ottawa, ON, Canada), via the Industrial Research Chair Program, with industry contributions from the Dairy Farmers of Canada (Ottawa, ON, Canada), British Columbia Dairy Association (Burnaby, BC, Canada), Westgen Endowment Fund (Abbotsford, BC, Canada), Intervet Canada Corporation (Kirkland, QC, Canada), Zoetis (Kirkland, QC, Canada), Novus International Inc. (Oakville, ON, Canada), BC Cattle Industry Development Fund (Kamloops, BC, Canada), Alberta Milk (Edmonton, AB, Canada), Valacta (St. Anne-de-Bellevue, QC, Canada), and CanWest DHI (Guelph, ON, Canada). The authors have not stated any conflicts of interest.

\section{REFERENCES}

Boogaard, B. K., S. J. Oosting, and B. B. Bock. 2008. Defining sustainability as a socio-cultural concept: Citizen panels visiting dairy farms in the Netherlands. Livest. Sci. 117:24-33. https://doi.org/ 10.1016/j.livsci.2007.11.004.

Charlton, G. L., S. M. Rutter, M. East, and L. A. Sinclair. 2011. Effects of providing total mixed rations indoors and on pasture on the behavior of lactating dairy cattle and their preference to be indoors or on pasture. J. Dairy Sci. 94:3875-3884. https://doi.org/ 10.3168/jds.2011-4172.

Charlton, G. L., S. M. Rutter, M. East, and L. A. Sinclair. 2013. The motivation of dairy cows for access to pasture. J. Dairy Sci. 96:4387-4396. https://doi.org/10.3168/jds.2012-6421.

Edmonson, A. J., I. J. Lean, L. D. Weaver, T. Farver, and G. Webster. 1989. A body condition scoring chart for Holstein dairy cows. J. Dairy Sci. 72:68-78. https://doi.org/10.3168/jds.S0022 -0302(89)79081-0.

Falk, A. C., D. M. Weary, C. Winckler, and M. A. G. von Keyserlingk. 2012. Preference for pasture versus freestall housing by dairy cattle when stall availability indoors is reduced. J. Dairy Sci. 95:64096415. https://doi.org/10.3168/jds.2011-5208.

Fisher, A. D., M. A. Crowe, P. O'Kiely, and W. J. Enright. 1997. Growth, behaviour, adrenal and immune responses of finishing beef heifers housed on slatted floors at 1.5, 2.0, 2.5 or $3.0 \mathrm{~m} 2$ space allowance. Livest. Prod. Sci. 51:245-254. https://doi.org/10.1016/ S0301-6226(97)00052-3.

Flower, F. C., and D. M. Weary. 2006. Effect of hoof pathologies on subjective assessments of dairy cow gait. J. Dairy Sci. 89:139-146. https://doi.org/10.3168/jds.S0022-0302(06)72077-X.
Franks, B. 2019. What do animals want? Anim. Welf. 28:1-10. https:/ /doi.org/10.7120/09627286.28.1.001.

Franks, B., and E. T. Higgins. 2012. Effectiveness in humans and other animals: A common basis for well-being and welfare. Adv. Exp. Soc. Psychol. 46:285-346.

Fregonesi, J. A., C. B. Tucker, and D. M. Weary. 2007. Overstocking reduces lying time in dairy cows. J. Dairy Sci. 90:3349-3354. https: //doi.org/10.3168/jds.2006-794.

Fregonesi, J. A., C. B. Tucker, D. M. Weary, F. C. Flower, and T. Vittie. 2004. Effect of rubber flooring in front of the feed bunk on the time budgets of dairy cattle. J. Dairy Sci. 87:1203-1207. https:// doi.org/10.3168/jds.S0022-0302(04)73270-1.

Haskell, M. J., K. Masłowska, D. J. Bell, D. J. Roberts, and F. M. Langford. 2013. The effect of a view to the surroundings and microclimate variables on use of a loafing area in housed dairy cattle. Appl. Anim. Behav. Sci. 147:28-33. https://doi.org/10.1016/j .applanim.2013.04.016.

Hindhede, J., J. T. Sørensen, M. B. Jensen, and C. C. Krohn. 1996. Effect of space allowance, access to bedding, and flock size in slatted floor systems on the production and health of dairy heifers. Acta Agric. Scand. A Anim. Sci. 46:46-53. https://doi.org/10.1080/ 09064709609410923.

Hötzel, M. J., C. S. Cardoso, A. Roslindo, and M. A. G. von Keyserlingk. 2017. Citizens' views on the practices of zero-grazing and cow-calf separation in the dairy industry: Does providing information increase acceptability? J. Dairy Sci. 100:4150-4160. https:// doi.org/10.3168/jds.2016-11933.

Huzzey, J. M., T. J. DeVries, P. Valois, and M. A. G. von Keyserlingk. 2006. Stocking density and feed barrier design affect the feeding and social behavior of dairy cattle. J. Dairy Sci. 89:126-133. https: //doi.org/10.3168/jds.S0022-0302(06)72075-6.

Krawczel, P. D., L. B. Klaiber, R. E. Butzler, L. M. Klaiber, H. M. Dann, C. S. Mooney, and R. J. Grant. 2012. Short-term increases in stocking density affect the lying and social behavior, but not the productivity, of lactating Holstein dairy cows. J. Dairy Sci. 95:4298-4308. https://doi.org/10.3168/jds.2011-4687.

Ledgerwood, D. N., C. Winckler, and C. B. Tucker. 2010. Evaluation of data loggers, sampling intervals, and editing techniques for measuring the lying behavior of dairy cattle. J. Dairy Sci. 93:51295139. https://doi.org/10.3168/jds.2009-2945.

Legrand, A. L., M. A. G. von Keyserlingk, and D. M. Weary. 2009 Preference and usage of pasture versus free-stall housing by lactating dairy cattle. J. Dairy Sci. 92:3651-3658. https://doi.org/10 $.3168 /$ jds.2008-1733.

Mogensen, L., C. C. Krohn, J. T. Sørensen, J. Hindhede, and L. H. Nielsen. 1997. Association between resting behaviour and live weight gain in dairy heifers housed in pens with different space allowance and floor type. Appl. Anim. Behav. Sci. 55:11-19. https: //doi.org/10.1016/S0168-1591(97)00041-5.

Munksgaard, L., M. B. Jensen, L. J. Pedersen, S. W. Hansen, and L. Matthews. 2005. Quantifying behavioural priorities - Effects of time constraints on behaviour of dairy cows, Bos taurus. Appl. Anim. Behav. Sci. 92:3-14. https://doi.org/10.1016/j.applanim 2004.11.005.

NFACC (National Farm Animal Care Council). 2009. Code of Practice for the Care and Handling of Dairy Cattle. Dairy Farmers of Canada, Ottawa, ON, Canada.

Nielsen, L. H., L. Mogensen, C. Krohn, J. Hindhede, and J. T. Sørensen. 1997. Resting and social behaviour of dairy heifers housed in slatted floor pens with different sized bedded lying areas. Appl. Anim. Behav. Sci. 54:307-316. https://doi.org/10.1016/S0168 -1591(96)01211-7.

NRC (National Research Council). 2001. Nutrient Requirements of Dairy Cattle. 7th rev. ed. Natl. Acad. Press, Washington, DC.

Ravagnolo, O., I. Misztal, and G. Hoogenboom. 2000. Genetic component of heat stress in dairy cattle, development of heat index function. J. Dairy Sci. 83:2120-2125. https://doi.org/10.3168/jds .S0022-0302(00)75094-6.

Robbins, J. A., M. A. G. Von Keyserlingk, D. Fraser, and D. M. Weary. 2016. Invited review: Farm size and animal welfare. J. Anim. Sci. 94:5439-5455. https://doi.org/10.2527/jas.2016-0805. 
Schuppli, C. A., M. A. G. von Keyserlingk, and D. M. Weary. 2014. Access to pasture for dairy cows: Responses from an online engagement. J. Anim. Sci. 92:5185-5192. https://doi.org/10.2527/ jas.2014-7725.

Schütz, K. E., F. J. Huddart, M. A. Sutherland, M. Stewart, and N. R. Cox. 2015. Effects of space allowance on the behavior and physiology of cattle temporarily managed on rubber mats. J. Dairy Sci. 98:6226-6235. https://doi.org/10.3168/jds.2015-9593.

Schütz, K. E., A. R. Rogers, N. R. Cox, and C. B. Tucker. 2009 Dairy cows prefer shade that offers greater protection against solar radiation in summer: Shade use, behaviour, and body temperature. Appl. Anim. Behav. Sci. 116:28-34. https://doi.org/10.1016/ j.applanim.2008.07.005.

Smid, A. M. C., E. E. A. Burgers, D. M. Weary, E. A. M. Bokkers, and M. A. G. von Keyserlingk. 2019. Dairy cow preference for access to an outdoor pack in summer and winter. J. Dairy Sci. 102:1551-1558. https://doi.org/10.3168/jds.2018-15007.

Talebi, A., M. A. G. von Keyserlingk, E. Telezhenko, and D. M. Weary. 2014. Reduced stocking density mitigates the negative effects of regrouping in dairy cattle. J. Dairy Sci. 97:1358-1363. https:// doi.org/10.3168/jds.2013-6921.

Telezhenko, E., M. A. G. von Keyserlingk, A. Talebi, and D. M. Weary. 2012. Effect of pen size, group size, and stocking density on activity in freestall-housed dairy cows. J. Dairy Sci. 95:3064-3069. https://doi.org/10.3168/jds.2011-4953.

Tresoldi, G., D. M. Weary, L. Pinheiro Machado Filho, and M. A. G. von Keyserlingk. 2015. Social licking in pregnant dairy heifers. Animals (Basel) 5:1169-1179. https://doi.org/10.3390/ani5040404.

Tucker, C. B., L. Munksgaard, E. M. Mintline, and M. B. Jensen. 2018. Use of a pneumatic push gate to measure dairy cattle motivation to lie down in a deep-bedded area. Appl. Anim. Behav. Sci. 201:15-24. https://doi.org/10.1016/j.applanim.2017.12.018.
Tucker, C. B., A. R. Rogers, and K. E. Schütz. 2008. Effect of solar radiation on dairy cattle behaviour, use of shade and body temperature in a pasture-based system. Appl. Anim. Behav. Sci. 109:141-154. https://doi.org/10.1016/j.applanim.2007.03.015.

UBC AWP (University of British Columbia Animal Welfare Program). 2013. UBC Animal Welfare Program: SOP - HOBO Data Loggers. University of British Columbia, Vancouver, Canada. Accessed Aug. 31, 2017. http://lfs-awp.sites.olt.ubc.ca/files/2013/11/SOP -HOBO-Datalogger-november-2013.pdf.

Val-Laillet, D., D. M. Veira, and M. A. G. von Keyserlingk. 2008. Short communication: Dominance in free-stall-housed dairy cattle is dependent upon resource. J. Dairy Sci. 91:3922-3926. https:// doi.org/10.3168/jds.2008-1332.

von Keyserlingk, M. A. G., A. Amorim Cestari, B. Franks, J. A. Fregonesi, and D. M. Weary. 2017. Dairy cows value access to pasture as highly as fresh feed. Sci. Rep. 7:44953. https://doi.org/10.1038/ srep44953.

von Keyserlingk, M. A. G., D. Olenick, and D. M. Weary. 2008. Acute behavioural effects of regrouping dairy cows. J. Dairy Sci. 91:10111016. https://doi.org/10.3168/jds.2007-0532.

Wang, X., G. Zhang, and C. Y. Choi. 2018. Effect of airflow speed and direction on convective heat transfer of standing and reclining cows. Biosyst. Eng. 167:87-98. https://doi.org/10.1016/j .biosystemseng.2017.12.011.

\section{ORCIDS}

A. M. C. Smid ๑ https://orcid.org/0000-0001-9810-4032

D. M. Weary @ https://orcid.org/0000-0002-0917-3982

M. A. G. von Keyserlingk @ https://orcid.org/0000-0002-1427-3152

\section{APPENDIX}

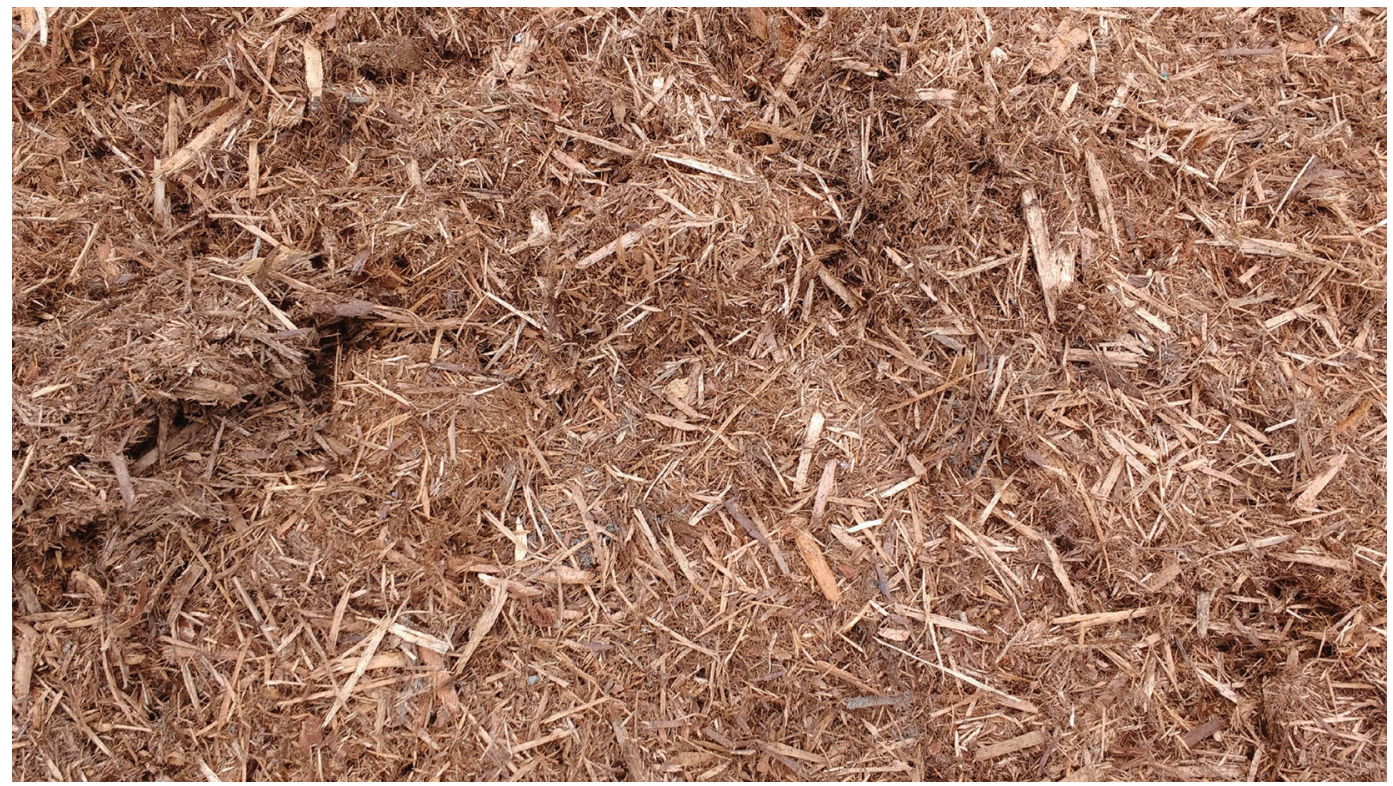

Figure A1. Close-up of the wood chips used as bedding for the outdoor open pack. 